\title{
Low sero-prevalence of Contagious Bovine Pleuropneumonia (CBPP) in bulls originated from Borena Pastoral Area of Southern Ethiopia
}

\author{
Gezahegn Alemayehu ${ }^{1, *}$, Samson Leta ${ }^{2}$, Berhanu Hailu ${ }^{1}$ \\ ${ }^{1}$ College of Veterinary Medicine, Samara University, Samara, Ethiopia \\ ${ }^{2}$ Oromia Agricultural Research Center, Adami-Tulu, Ethiopia
}

Email address:

gezahegnayalew@yahoo.com (G. Alemayehu)

\section{To cite this article:}

Gezahegn Alemayehu, Samson Leta, Berhanu Hailu. Low Sero-Prevalence of Contagious Bovine Pleuropneumonia (CBPP) in Bulls Originated from Borena Pastoral Area of Southern Ethiopia. Animal and Veterinary Sciences. Vol. 2, No. 6, 2014, pp. $213-217$. doi: 10.11648/j.avs.20140206.19

\begin{abstract}
Contagious bovine pleuropneumonia (CBPP) is a highly infectious cattle disease, which is widespread in pastoral areas of Africa and it is a major problem for Ethiopian livestock. Cross-sectional study was conducted in 2011 on bulls' originated from Borena pastoral area to determine seroprevalence of CBPP. Of the total 40 batches tested for the presence of antibodies using c-ELISA, 25(62.5\%) of them contained at least one seropositive bull. From the total of 38,187 bulls tested, $150(0.4 \%)$ bulls were found positive. There was statistically significant $\left(\chi^{2}=63.45, \mathrm{df}=9, \mathrm{p}=0.000\right)$ difference in the occurrence of CBPP among the 10 sites of feedlots operation at individual animal level. In both at herd and individual level, the highest CBPP prevalence was recorded in herd size $>1000$, and the difference was found statistically significant $(\mathrm{P}<0.05)$. There was statistically significant $\left(\chi^{2}=23.73, \mathrm{df}=9, \mathrm{p}=0.005\right)$ difference of CBPP prevalence between months of the year. The present low prevalence CBPP in the cattle feedlots indicate the disease is decreasing progressively in Borena pastoral area. This offered a great opportunity to livestock producers through live animal and meat export. Prompt diagnosis, isolation and stamping out of the outbreaks, intensive surveillance, followed by strict cattle movement control should be implemented by Ethiopian Veterinary Services to eradicate the disease.
\end{abstract}

Keywords: Borena, Bull, CBPP, Ethiopia, Pastoral Area

\section{Introduction}

Contagious Bovine Pleuropneumonia (CBPP) is a highly infectious cattle disease, which is caused by Mycoplasma mycoides subsp. mycoides SC (small colony, bovine biotype), is one of the major constraints to cattle-raising and trade in Africa. Contagious bovine pleuropneumonia is widespread in pastoral areas of Africa and it is a major problem for Ethiopian livestock [1]. Although CBPP was once found worldwide, it was eradicated from most continents, by the mid- $20^{\text {th }}$ century. Its incidence also began to decline in Africa by the 1970s. However, because of the economic and financial difficulties that affected the ability of governments to adequately fund Veterinary Services, the disease came back in the late 1980s and early 1990s [2,3]. Major CBPP epidemics have been experienced in Eastern, Southern, and West Africa over the last few years. It currently affects 27 countries in Africa at an estimated annual cost of US \$2 billion [4]. A total of 2,719 outbreaks were reported in Africa between 1995 and 2002.Countries in East Africa reported 66\% of the total outbreaks (58\% in Ethiopia and Tanzania and $8 \%$ in other countries in the region) [2].

M. mycoides SC is mainly transmitted from animal to animal in aerosols. This organism also occurs in saliva, urine, fetal membranes and uterine discharges. Carrier animals, including subclinically infected cattle, can retain viable organisms in encapsulated lung lesions (sequestra) for up to two years. These animals may shed organisms, particularly when stressed [3]. Cattle movements are responsible for the transmission of the CBPP from one herd, region or country to others. Close, repeated contact is generally thought to be necessary for transmission; however, $M$. mycoides SC might be spread over longer distances (50 to 200 meters) if the climatic conditions are favorable [1].

The livestock subsector has an enormous contribution to 
Ethiopia's national economy and livelihoods of many Ethiopians, and still promising to rally round the economic development of the country. Livestock plays vital roles in generating income to farmers, creating job opportunities, ensuring food security, providing services, contributing to asset, social, cultural and environmental values, and sustain livelihoods. The subsector contributes about $16.5 \%$ of the national Gross Domestic Product (GDP) and $35.6 \%$ of the agricultural GDP [5]. It also contributes $15 \%$ of export earnings and $30 \%$ of agricultural employment [6]. The livestock subsector currently support and sustain livelihoods for $80 \%$ of all rural population. The GDP of livestock related activities valued at birr 59 billion [5]. However, transboundary animal diseases such as CBPP constrain the livestock sector of the country and affect livelihoods via their impact on animal health, animal food production, availability and quality. Furthermore, CBPP is one of the major diseases in Ethiopia that hampering export of livestock and livestock products to the international markets since long time.

Pastoral areas output underpins almost all of Ethiopia's live animal and meat exports. A large percentage of the cattle and beef meat exported from Ethiopia originates from Borena pastoral area [7]. However, this area as whole infected since long time, is an endemic area [8]. Contagious Bovine Pleuropneumonia was number one important disease in Borena cattle [9]. Prevalence rates of ranging between 9.4 to $74 \%$ were recorded in Borena cattle in 204 and 1995 respectively $[10,11]$. Even though rinderpest eradication has been achieved in Ethiopia, the persistence of CBPP effectively limits trade opportunities. A constraint to this potential for market access is the ability of the country to meet ever-increasing requirements for food safety and sanitary and phytosanitary standards (SPS) requirement of World Trade Organization (WTO). It follows that attempts to improve international market access for livestock producers in the developing world must include improving the capacity of these countries to operate within the SPS Agreement and the OIE's Terrestrial Animal Health Code, while ensuring that the requirements are equitable, justifiable and effective.

Increased international trade in livestock and livestock products is also an argument for more support for the veterinary services in the control of tarnsboundary animal diseases (TADs) such as CBPP. Despite widespread recognition of the prime importance of livestock for pastoral societies, TADs such as CBPP continue to be an effective brake on marketing opportunities for these often poor communities. The occurrence of such diseases impacts both poor and richer livestock producers by marginalizing them from higher price livestock markets and restricting their capacity for value-added trade [12]. Movement restrictions and local quarantines mean the closure of livestock markets and reduced or no opportunities for sale of live animals and possibly meat and other products. In addition to the measurable economic impact on a national economy the inability to sell their animal can bring severe hardship to a pastoral family with no other income of sources of support $[13,14]$.
In order to secure international market, Ethiopian government needs to meet WTO requirement by demonstrating their responses towards CBPP control. The challenge of CBPP control in endemic settings will require active partnerships to overcome the limitations of insufficient epidemiological information from the country on the basis of which to develop targeted measures, and limited capacity and national resources to apply control measures based on mass vaccination or effective movement control. The admission of large numbers of bulls into feedlots facilities for a period of time ranging from 3 to 4 months offered an excellent opportunity to study CBPP prevalence in the Borena pastoral area of Southern Ethiopia where the bulls were originated. Therefore, the objective of this study was to determine the seroprevalence of CBPP in bulls originated from Borena pastoral area of Southern Ethiopia.

\section{Material and Methods}

\subsection{Study Areas}

The study was conducted on bulls at finishing phase for export in East Shewa zone brought from Borena pastoral area. Borena pastoral area of Southern Ethiopia, located between $03^{0} 37^{\prime} 23.8^{\prime \prime}$ to $05^{0} 02^{\prime} 52.4^{\prime \prime}$ North and $37^{0} 56^{\prime} 49.4^{\prime \prime}$ to $39^{\circ}$ $01^{\prime} 1^{0} 1^{\prime \prime E a s t, ~ i n ~ O r o m i a ~ R e g i o n a l ~ S t a t e s . ~ T h e ~ a l t i t u d e ~ r a n g e s ~}$ from 970 masl in the south bordering Kenya to 1693 masl in the Northeast. The Borana pastoral area represents a vast lowland area, covering about $95,000 \mathrm{~km}^{2}$ [15]. Livestock is an integral part of the Borana people that serve several purposes: as source of food, income generation and social prestige [16]. East Shewa Zone is located in the central parts of Ethiopia. Absolute location of the Zone extends from $7^{0}$ $33^{\prime} 50^{\prime \prime} \mathrm{N}$ to $9^{0} 08^{\prime} 56^{\prime \prime} \mathrm{N}$ and $38^{\circ} 24^{\prime} 10^{\prime \prime} \mathrm{E}$ to $40^{\circ} 05^{\prime} 34^{\prime \prime} \mathrm{E}$ which indicate that this zone is located in tropical climatic zone though the climate is influenced by altitudinal variation. The total area of East Shewa Zone is approximately $9,633.52 \mathrm{~km}^{2}$. The altitude ranges from 500 to 4307 meter above mean sea level. The Zone can be categorized under rift Area of Ethiopia since about $93 \%$ of the total area of the zone is completely located in rift Area.

\subsection{Study Design and Subject}

Cross-sectional study was conducted for one year period from January 2011 to December 2011 to determine seroprevalence of CBPP on 40 batches of bulls admitted in 20 different feedlots facilities. A total of 38,187 apparently health bulls intended for export found in 10 sites were included in the study. The bulls were originated from Borena pastoral area and on finishing stage for export in East Shewa zone. Those animals were not subjected to veterinarian inspection and selection during purchase in the markets and they were not tested for any diseases before they were moved into feedlots. Bulls were transported by truck from Borena production area to feedlots in East Showa zone. As part of SPS requirements and rules and regulations of animal quarantine it is a requirement that all animals being exported 
to Arabian countries are tested for CBPP; therefore, all bulls being exported were subjected to blood sample collection. All animals used for study were male with 3-5 years age category and vaccinated for CBPP.

\subsection{Serum Samples Collection and Processing}

Serum samples $(n=38,187)$ collected for one year $(2011)$ period for certifications purposes from bulls were used for seropositivity determination. Blood samples were aseptically collected using $10 \mathrm{ml}$ plain vacutainer tubes from apparently healthy bulls through jugular venipuncure. The tubes were then labeled with tag number of animals and kept protected from direct sun light in slant position until the blood clotted and sera were separated. The clotted blood or separated sera were transported to National veterinary institute (NVI) laboratory and National Animal Health Diagnostic and Investigation Centre (NAHDIC) for investigation. Serum samples were examined for antibodies to using a Competitive Enzyme Linked Immuno-Sorbent Assay (C-ELISA) to identify CBPP seropositive and negative animals following the manufacturer's instructions. For economic reasons, the tests were interpreted as negative for results below $45 \%$ and positive above $45 \%$.

\subsection{Data Analysis}

Data were classified, filtered, coded using MS Excel, and was transferred to Statistical Package for Social Sciences Software version 20. Descriptive statistics was performed to summarize seroprevalence of CBPP at batch and individual level. The $\chi^{2}$ test was used to assess risk factors at feedlots. In all analysis confidence level was held at $95 \%$ and $\mathrm{P} \leq 0.05$ was set for significance.

\section{Results}

Table 1. Batches Seroprevalence of CBPP in Relation to site of feedlot operation and herd sizes

\begin{tabular}{|c|c|c|c|c|c|}
\hline Variables & Number of tested & Number of positive (\%) & $95 \% \mathrm{CI}$ & $x^{2}$ & P-value \\
\hline \multicolumn{6}{|l|}{ Sites } \\
\hline Dera & 3 & $3(100)$ & $100-100$ & & \\
\hline Modjo & 1 & 0 & $0.0-97.5$ & & \\
\hline Adama & 16 & $8(50)$ & $24.7-75.3$ & & \\
\hline Wanji & 4 & $2(50)$ & $6.8-93.2$ & & \\
\hline Koshe & 7 & $4(57.1)$ & $18.4-90.1$ & 11.35 & 0.252 \\
\hline Mekie & 3 & $3(100)$ & $100-100$ & & \\
\hline Awash Melkasa & 1 & $0(0)$ & $0-97.5$ & & \\
\hline Awash 7 killo & 2 & $2(100)$ & $100-100$ & & \\
\hline Nahmaled & 2 & $2(100)$ & $100-100$ & & \\
\hline Adami Tulu & 1 & $1(100)$ & $100-100$ & & \\
\hline \multicolumn{6}{|l|}{ Herd size } \\
\hline$<500$ & 13 & $4(30.8)$ & $9.1-61.4$ & & \\
\hline $500-100$ & 11 & $6(54.5)$ & $23.4-83.3$ & 12.548 & 0.002 \\
\hline$>1000$ & 16 & $15(93.8)$ & 69.8-99.8 & & \\
\hline
\end{tabular}

Of the total 40 batches tested for the presence of antibodies using c-ELISA, 25(62.5\%) of them contained at least one seropositive bull. From the total of 38,187 bulls tested, $150(0.4 \%)$ bulls were found positive. At batches level, highest prevalence was recorded in feedlots found Dera, Mekie, Awash 7 killo, Nahmaled and Adami Tulu sites(100\%) and lowest was recorded in feedlots found Modjo and Awash Melkasa sites. At individual animal level, the highest seropositivity was recorded in Mekie (1.1\%), and the lowest was recorded in Modjo site $(0.0 \%)$. There was statistically significant $\left(\chi^{2}=63.45, \mathrm{df}=9, \mathrm{p}=0.000\right)$ difference in the occurrence of CBPP among the 10 sites of feedlots operation at individual animal level. Among the three herd size categories, in both at herd and individual level, the highest CBPP prevalence was recorded in herd size $>1000$, and the difference was found statistically significant $(\mathrm{P}<0.05)$ (Table 1 and Table 2). At individual animal level highest prevalence was recorded in July month (0.7) and lowest was recorded in June $(0.1 \%)$ (Fig.1). There was statistically significant $\left(\chi^{2}=23.73, \mathrm{df}=9, \mathrm{p}=0.005\right)$ difference of CBPP prevalence between months of the year.

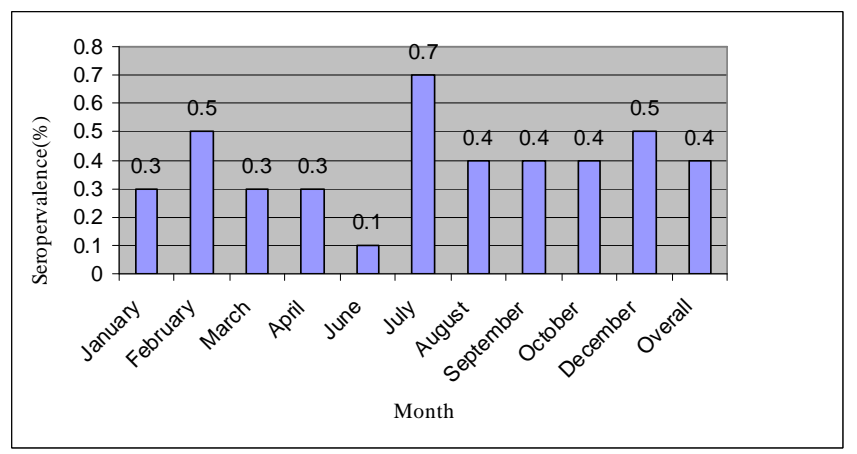

Figure 1. Monthly seroprevalence of CBPP in bull originated from Borena pastoral area in 2011 
Table 2. Seroprevalence of CBPP in Borena bulls in relation to site of feedlot operation and herd sizes

\begin{tabular}{|c|c|c|c|c|c|}
\hline Variables & Number of tested & Number of positive $(\%)$ & $95 \% \mathrm{CI}$ & $x^{2}$ & P-value \\
\hline \multicolumn{6}{|l|}{ Sites } \\
\hline Dera & 2090 & $14(0.7)$ & $0.3-1.0$ & \multirow{10}{*}{63.45} & \multirow{10}{*}{0.000} \\
\hline Modjo & 484 & $0(0.0)$ & $0.0-0.0$ & & \\
\hline Adama & 12180 & $38(0.3)$ & $0.2-0.4$ & & \\
\hline Wanji & 2136 & $4(0.2)$ & $0.0-0.4$ & & \\
\hline Koshe & 6399 & $19(0.3)$ & $0.2-0.4$ & & \\
\hline Mekie & 3544 & $40(1.1)$ & $0.8-1.5$ & & \\
\hline Awash Melkasa & 2417 & $6(0.2)$ & $0.0-0.4$ & & \\
\hline Awash 7 killo & 4338 & $15(0.3)$ & $0.2-0.5$ & & \\
\hline Nahmaled & 3469 & $10(0.3)$ & $0.1-0.5$ & & \\
\hline Adami Tulu & 1130 & $4(0.4)$ & $0.0-0.7$ & & \\
\hline \multicolumn{6}{|l|}{ Herd size } \\
\hline$<500$ & 3663 & $10(0.3)$ & $0.1-0.5$ & \multirow{3}{*}{14.40} & \multirow{3}{*}{0.001} \\
\hline $500-1000$ & 8954 & $18(0.2)$ & $0.1-0.3$ & & \\
\hline$>1000$ & 25570 & $122(0.5)$ & $0.4-0.6$ & & \\
\hline
\end{tabular}

\section{Discussion}

The low CBPP prevalence $(0.4 \%)$ in our study was comparable with the reports from Senegal $0.43 \%$ [17], Nigeria $0.51 \%$ [18]. On the other hand, the result of this study was lower than the overall seroprevalence of $21.05 \%$ in Guinea [19], 2.9\% in Burkina Faso, 5.4\% in Mauritania and $10.5 \%$ in Mali [20], $10.3 \%$ in Somali region [21], 4\% in west Wellega [22] and. Previous study conducted by Kassaye and Molla (23) during a period of 2010 -2011 reported a 4\% seroprevalence of CBPP at export quarantine centers in and around Adama, Ethiopia. A relatively higher seroprevalence was reported by Kassaye and Molla (2012); however, the bulls used for the study has no history of vaccination against CBPP. Higher seroprevalences were also recorded in previous studies in Borena zone with $5.1 \%$ and $74 \%$ prevalence by Issa, [10] and Roger and Yigezu [11] respectively. The lower seroprevalence in this study might be due to the fact that ongoing annual mass vaccination program might decreases the disease at pastoral production level. This fact is supported by Masiga and Domenech, [24] in which annual mass vaccination has been used with good results in East Africa and much of West Africa. Furthermore, bulls intended for finishing were purchased based on their good body condition and health, the probability purchasing chronically ill or recovered animals with poor body condition is therefore very low. This might also account for lower prevalence of diseases in the feedlots. In Ethiopia antibiotic is used for the treatment of the disease for long time. This could be lower seroprevalence of the disease by reducing a detectable serological response [25].

The seropositivity of CBPP varied between study sites and the variations were statistically significant $(p<0.05)$. This variation might occur due to the difference in biosecurity measures used and cattle population densities in feedlots. The increase of CBPP prevalence as herd size increase seen in this study may be due to the fact that risk of an individual animal introduced infection into negative herd may increase with herd size, and lateral spread of infection within the herd may be favored.

Similarly, there was statistically significant $(p=0.005)$ difference between month of the year with highest seropositivity on July $(0.7 \%)$ and lowest on June $(0.1 \%)$. The higher prevalence of the diseases in rainy month of July might be due to the fact that the disease is less prevalent in dry climates than in humid ones due to infected droplets can be inactivated by ultraviolet light as indicated by Provost et al. [26].

The present low prevalence CBPP in the cattle feedlots indicate the disease is decreasing progressively in Borena pastoral area. Government strategy in animal health is provision of preventive services through mass vaccination of CBP and antibiotic treatment play great role for the reduction of disease in Borena pastoral area. This offered a great opportunity to livestock producers through live animal and meat export. This low prevalence of CBPP at pastoral production level is achieved mainly through mass vaccination and antibiotic treatments. However, regular reintroduction of cattle from neighboring countries or herds where the disease remains endemic, will maintain the infection and clinical disease will develop again as soon as the vaccination campaigns cease [1]. Therefore, mass blanket vaccinations coupled with prompt diagnosis, isolation and stamping out of the outbreaks, intensive surveillance, followed by strict cattle movement control should be implemented by Ethiopian Veterinary Services to eradicate the disease. As Borena pastoral area is the main source of live cattle and meat export. Eradication of CBPP from Borena pastoral areas are therefore increases the participation of the country in the lucrative markets for livestock and livestock products.

It should be noted that the values presented in this study obtained from serum sample collected from bulls which were selected based on good body condition. This might not demonstrate the true prevalence of CBPP in Borena pastoral production area. Therefore, clinical diagnosis, serological surveillance and post-mortem examination of lesions at abattoir are essential at primary production level to know the true prevalence of CBPP. 


\section{Acknowledgment}

We would like to express our gratitude to all feedlots owners found in East Shewa Zone for their all round cooperation during survey. We are also very grateful to Dr. Kimiya Mohamed and Dr. Tegist Bantirugu Adama plant and animals quarantine service center senior inspectors.

\section{References}

[1] Masiga, W.N., Domenech, J. \& Windsor, R.S. 1996. Manifestation and epidemiology of contagious bovine pleuropneumonia in Africa. In Animal mycoplasmoses and control. Rev. sci. tech. Off. int. Epiz., 15 (4), 1283-1308.

[2] Tambi., N.E., Maina, W.O. and Ndi, C. 2006. An estimation of the economic impact of contagious bovine pleuropneumonia in Africa. Rev. sci. tech. Off. int. Epiz., 25 (3), 999-012.

[3] Rovid, S.A. (2008): Contagious bovine pleuropneumonia. The center for food security and public health, Iowa State University. College of Veterinary Medicine. http://www.cfsph.iastate.edu. Accessed April 2012.

[4] Otte, M.J., Nugent, R. and Mcleod, A. 2004. Transboundary animal diseases: socio-economic impacts and institutional response. FAO Livestock policy discussion paper 9.

[5] [5]Metaferia, F., Cherenet, T., Gelan, A., Abnet, F., Tesfay, A., Ali, J.A., Gulilat, W., 2011. A Review to Improve Estimation of Livestock Contribution to the National GDP. Ministry of Finance and Economic Development and Ministry of Agriculture, Addia Ababa, Ethiopia.

[6] Behnke, R., 2010. The Contribution of Livestock to the Economies of IGAD Member States: Study Findings, Application of the Methodology in Ethiopia and Recommendations for Further Work. IGAD LPI Working Paper 02-10. Great Wolford, UK: Odessa Centre, IGAD Livestock Policy Initiative. In.

[7] Farmer, E. 2010. End Market Analysis of Ethiopian Livestock and Meat. A Desk Study Micro report 164.

[8] Afework, Y. 2000. Analysis of CBPP situation in Ethiopia, Past and Present. Ministry of Agriculture, Addis Ababa, Ethiopia.

[9] Rufael, T., Catley, A., Bogale, A., Sahle, M. and Shiferaw., Y. 2008. Foot and Mouth Disease in Borana Pastoral Area, Southern Ethiopia. Trop Anim Health Prod, 40, 29-38. Doi:10.1007/s11250-007-9049-6.

[10] Issa A. 2004. Epidemiological study of contagious bovine pleuropneumonia in Borena pastoral area using Complement fixation test and Competitive enzyme-linked immunosorbent assay (ELISA). (MSC thesis). Addis Ababa University, Faculty of Veterinary Medicine, Debre zeit, Ethiopia.

[11] Roger, F and Yigezu, L. 1995. The Situation of CBPP in Ethiopia. CIRAD-EMVT and National Veterinary Institute, Ethiopia.

[12] FAO 2002. Improved animal health for poverty reduction and sustainable livelihoods. FAO Animal Production and Health Paper 153. Rome.
[13] Steffen, P, Shirwa, A.H. and Addou, S.I. 1998. The livestock embargo by Saudi Arabia: a report on the economic, financial, and social impact on Somaliland and Somalia. FEWS NET.

[14] Holleman, C.F. 2002. The socio-economic implications of the livestock ban in Somalia. Famine Early Warning Area Network: Nairobi, Kenya.

[15] Coppock, D. L. 1994. The Borana Plateau of Southern Ethiopia: Synthesis of Pastoral Research Development and Change, 1980-91. (International Livestock Centre for Africa, Addis Ababa)

[16] Desta, S. 1999. Diversification of Livestock assets for risk management in the Borana pastoral Area of Southern Ethiopia, PhD thesis, Utah State University, Logan, Utah. pp: 10-31

[17] Mbengue MB., J. Sarr, Fall Massal. 2013. Sero epidemiological studies on contagious bovine leuropneumonia (CBPP) in Senegal. American Journal of Research Communication, 1(3): 190-199.

[18] Nawathe D.R. 1992. Resurgence of contagious bovine pleuropneumonia in Nigeria. Rev. sci. tech. Off. int. Epiz., 11 (3), 799-804.

[19] Soromou, L.W. Dabo, D. Cissé, M. Sidimé, Y. Keyra, M. Sylla M. K., Baldé,, A. Haba P.F. and Kéita F. 2014. Seroprevalence of contagious bovine pleuropneumonia in the prefecture of Dabola, Upper Guinea. Africa Journal of Animal and Biomedical Sciences 8(1).

[20] Kane M. (2002). Etude historique sur la péripneumonie contagieuse bovine au Burkina Faso, Côte d'Ivoire, Guinee, Mali, Mauritanie, Niger et Sénégal. Consultancy report produced for the African Union Interafrican Bureau for Animal Resources-Pan African Programme for the Control of Epizootics. AU/IBAR-PACE, Nairobi.

[21] Mekonnen, G., G. 2004. Serological, Clinical and Participatory Epidemiological Survey of Contagious Bovine Pleuropneumonia in Somali Region, Ethiopia (MSC thesis). Addis Ababa University, Faculty of Veterinary Medicine, Debre zeit, Ethiopia.

[22] Fikru, R. 2001. Herd prevalence of CBPP, bovine tuberculosis and Dictyocaulosis in Budju woreda, West Wellega. (DVM thesis). Addis Ababa University, Faculty of Veterinary Medicine, Debre zeit, Ethiopia.

[23] Kassaye D and Molla W (2012). Seroprevalence of contagious bovine pleuropneumonia at export quarantine centers in and around Adama, Ethiopia. Trop. Anim. Health. Prod. 45(1):275-9

[24] Masiga, W.N. and Domenech, J. 1995. Overview and epidemiology of contagious bovine pleuropneumonia in Africa. Rev. sci. tech. Off. int. Epiz., 14 (3), 611-620.

[25] OIE 2009. Contagious Bovine Pleuropneumonia.. Paris. Scientific.Dept@Oie.Int. Accessed April 2011.

[26] Provost, A., Perreau, P., Bréard, A., L E Goff, C, Martel, J.L. \& Cottew, G.S. 1987. Contagious bovine pleuropneumonia. In Mycoplasmoses of ruminants. Rev. sci. tech. Off. int. Epiz., 6 (3), 625-679. 